\title{
Wound healing potential: evaluation of molecular profiling and amplification of Lucilia sericata angiopoietin-1 mRNA mid-part
}

\author{
Hamzeh Alipour ${ }^{1,2}$, Marziae Shahriari-Namadi ${ }^{*}$, Saeedeh Ebrahimi ${ }^{1}$ \\ and Mohammad D. Moemenbellah-Fard ${ }^{1,2^{*}}$ (D)
}

\begin{abstract}
Objective: High prevalence of chronic ulcers and the burden of disease necessitate the increasingly significant production of new recombinant proteins in the world. The angiopoietin-1 enzyme is a part of the growth factors group which is secreted by Lucilia sericata (Diptera: Calliphoridae) larvae when they meet lesions to ensure maggot therapy. It is one of the most potent proteins in wound healing. Given its essential role, the angiopoietin-1 gene of L. sericata was characterized, which provided some necessary information on its identity.

Results: The mid-part of the angiopoietin-1 mRNA sequence was thus characterized based on the design of different primers such as exon-exon junction, conserved regions, and specific region primers via conventional polymerase chain reaction (PCR). Its structural features were configured by in silico method. The sequence of mid-part (390 bp) of angiopoietin-1 was determined empirically, and BLAST analysis unraveled its high identity (85\%) with the sequence of angiopoietin-1 mRNA of the larval housefly, Musca domestica. The homology of this enzyme also exhibited that its nucleic acid sequence was very similar to the domains of angiopoietin-1 in Lucilia cuprina. The current data are instructive and critical to evaluate the action of this enzyme in recombinant protein production in future molecular studies on wound healing.
\end{abstract}

Keyword: Wound healing, Therapy, Amplification, Lucilia sericata, Angiopoietin, Diptera, Larvae

\section{Introduction}

Angiopoietin genes foster wound healing [1]. The angiopoietin-1 enzyme is a portion of the growth factors (GF) group implicated in pre- and neo-natal vessel formation (angiogenesis) and regulating a plethora of cellular and extracellular matrix processes [2]. It involves a multiple of other regulatory roles in the endothelial cells, which are conducive to the cell generation and

\footnotetext{
*Correspondence: m.shahriarinamadi@yahoo.com; momenbf@sums.ac.ir; momenbf@yahoo.com

1 Department of Medical Entomology, School of Health, Shiraz University of Medical Sciences, Shiraz, Iran

${ }^{2}$ Research Center for Health Sciences, Institute of Health, Shiraz University of Medical Sciences, Shiraz, Iran
}

development of extracellular matrix [3]. A study showed the angiopoietin-1 enzyme had different activities concerning the growth stages involving various cell types while living organisms are faced with wound stress [4]. Two studies have demonstrated that more organ injury and fibrosis arise following elevated, inefficient angiogenesis $[5,6]$. The signal of this enzyme is directly exhibited in angiogenesis, as a result of which new blood capillaries form from previous veins and arteries [7]. Angiogenesis enzymes move forward through budding, endothelial cell movement, proliferation, and capillary deformity and stability. They are conducive to assemblage and disassemblage of the interior lining of blood vessels [8]. Angiopoietin-1 cytokines affect the control of microvascular porosity, dilation, and constriction by

(c) The Author(s) 2020. This article is licensed under a Creative Commons Attribution 4.0 International License, which permits use, sharing, adaptation, distribution and reproduction in any medium or format, as long as you give appropriate credit to the original author(s) and the source, provide a link to the Creative Commons licence, and indicate if changes were made. The images or other third party material in this article are included in the article's Creative Commons licence, unless indicated otherwise in a credit line to the material. If material is not included in the article's Creative Commons licence and your intended use is not permitted by statutory regulation or exceeds the permitted use, you will need to obtain permission directly from the copyright holder. To view a copy of this licence, visit http://creativeco mmons.org/licenses/by/4.0/. The Creative Commons Public Domain Dedication waiver (http://creativecommons.org/publicdomain/ zero/1.0/) applies to the data made available in this article, unless otherwise stated in a credit line to the data. 
alarming the smooth muscle cells that have surrounded the capillaries.

Four angiopoietins have been identified as ANGPT1, ANGPT2, ANGPT3, and ANGPT4 [9, 10]. Various extrinsic and intrinsic agents could result in such chronic ailments as diabetic wounds, thermal and radiation burns, injuries, geriatric lesions, and other infection lesions such as leishmaniasis [11], which lead the global prevalence of wounds. These are often chronic and resistant to treatment. Almost $15 \%$ of patients with diabetes suffering from foot ulcers, their legs are amputated due to disease complications. That is, a foot is globally amputated due to diabetes every $30 \mathrm{~s}$, while $80 \%$ of these cases are preventable [12]. Antibiotic-resistant bacterial infections that cause them are the most problematic subject available at burn centers. Multiple of these microorganisms have long been associated with complications in patients admitted to burn therapeutic centers [13, 14]. Recently, the effect of the angiopoietin- 1 has been implicated in the healing of cerebral malaria [15] and eye diseases [16]. Larval (maggot) therapy can be used in the treatment of infectious and diabetic wounds, bedsores, abscessic burns, some types of cancer and bone infection [17]. In 1929, William Beer of Johns Hopkins initiated the first innovation in maggot therapy. In the 1940s, advances in the production and use of the antibiotics reduced the related research about maggot therapy [18]. The performed clinical studies at the University of California in 1989 showed that this method was very effective in improving the wound healing in infections and gangrene [19]. By comparison with the antibiotic-resistant bacterial strains, the maggot therapy is considered as a promising method. Lucilia sericata larvae secrete different enzymes which are used in wound healing where one of them is angiopoietin-1. Therefore, maggot therapy is recommended as a selective therapeutic approach due to the diminished risk of damage to the vital organs following infections after surgical operations, speed of treatment, full recovery in patients and the limited use of antibiotics [20].

Further, the use of the L. sericata larvae in maggot therapy has been approved by the federal drug administration (FDA) in 2004 [21]. Therefore, the detection and identification of the secreted enzymes by larvae are informative in the design and production of new drugs in the future. One of these enzymes is angiopoietin-1-1, which has a role in angiogenesis and also stimulates growth factors [22].

Lucilia sericata distribution is confined to Holarctic and Neotropical zones [23, 24]. Its dispersion in Australia, Colombia, Argentina, Brazil, Chile, and Peru is reported elsewhere [25]. As well as its presence in Iran [26], $L$. sericata is regarded as a synanthropic species close to human residential areas. It is a necrophilic greenbottle insect from the Calliphoridae family [27]. Clinically, two significant effects of larval therapy, including antibacterial compounds secretion and their debridment activities have been ascribed to them [20]. This study aimed to implement the mid-part amplification of angiopoietin-1gene from $L$. sericata larvae as a potential element in wound healing.

\section{Methods \\ Rearing of Lucilia sericata larvae}

Experiments were conducted on the first instar of $L$. sericata maggots from a colony that had been brought up under constant conditions in the School of Health insectarium, Shiraz University of Medical Sciences (SUMS), Shiraz, Iran. Adult blowflies were encountered to a $12-\mathrm{h} \mathrm{L} / \mathrm{D}$ cycle at a relative humidity of $40-50 \%$ under $18-25^{\circ} \mathrm{C}$. The larvae were nourished with ground chicken liver. Accurate species identification was routinely confirmed using morphological and molecular tools.

\section{Primer design}

The $L$. sericata genome has not been sequenced yet. Therefore, primers were designed based on our previous studies [20, 28]. The mRNA sequences of Angiopoietin-1 from disparate insects like Aedes aegypti (XM_021846146), Musca domestica (XM_020038499), Drosophila arizonae (XM_018013154) and Bombyx mori (XM_004933073), were first obtained from NCBI and aligned using the Clustal Omega computer program (Fig. 1). Following careful consideration, two regions were selected to design gene-specific primers (GSPs). Two exon junction primers AnF1 (5'-AATATATTGGAG TTTATCGG-3') and AnR390 (5'-CGATATACACGA GGCAGTAG-3') were attributed as forward and reverse primers, respectively, to determine the middle part of the target gene. The anticipated amplicon size was $390 \mathrm{bp}$. Primers were designed by Gene Runner 0.04, Oligo 0.7, and BLAST (online tool) software.

\section{RNA extraction}

Total RNA was extracted from the salivary glands of the third instar cohort of $L$. sericata maggots applying the total RNA purification kit (High Pure RNA Isolation Kit, Roche Company, Germany). The extracted RNAs were treated by DNaseI (Roche Germany), both based on the manufacturer's instructions, and finally stored at $-70^{\circ} \mathrm{C}$.

\section{CDNA synthesis}

Extracted RNA was used for the first-strand cDNA synthesis. Then, RT (Reverse Transcription) reaction was 


\begin{abstract}
Bombyx
CTCCGAAAAAATGGACGAAGTTTGGGATGTGGTGGTTGGAACGAAGAGCTCTGTTGATGA 965

Aedes

TTCGGAGAAAATGGACGAAGTGTGGGACGTTGTCGTGGGAACCAAGAGCTCCGTTGACGA 977

Musca ATCGGAAAAAATGGATGAAGTATGGGATGTTGTGGTAGGCACGAAGTCGTCGGTGGATCA 716

Drosophila ATCTGAGAAAATGGACGAAGTCTGGGACGTTGTGGTGGGTACAAAGTCTTCGGTGGATCA 1058

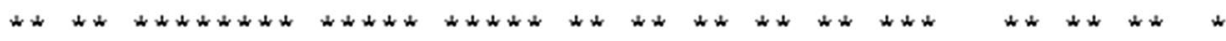

Bombyx

Aedes

TTTGGTACCGAAATCAGACGAACTACTCACGCAAACCCAACGACAAGAAAGGGCTATAGG 1025

Musca TCTGGTACCCAAATCGGATGCTCTTCTCACGCAGAACCAACGGCAGGAACGTGCCATCGG 1037 TTTACTACCCAAATCGGATGCTCTTCTGACCCAAACCCAACGCCAGGAAAGgGCTATTGG 776

Drosophila

TCTACTGCCCAAGTCGGATGCGCTGCTAACGCAGACGCAGCGGCAGGAACGTGCAATTGg 1118

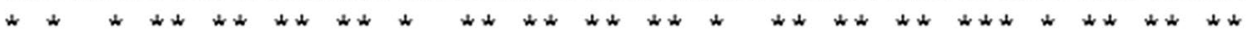

Bombyx

ACAGATACATAACGATTTGAGAGTTAAACCAATCTTATAATAGAAAACCTAGACATGGT 1085

Aedes CGAAATTCATCACGATTTGAAAACCAAAACGAACCTGATCATCAACAACTTGGACATGGT 1097

Musca

Drosophila TGAAATTCATCAGGATTTGAAAACGAAAACTAATTTGATTATCAATAACTTGGATATGGT 836 CGAAATCCATCAGGATCTGAAAACCAAAACGAATTTAATAATTAATAACTTGGACATGGT 1178

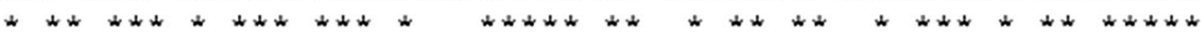

Bombyx

Aedes

Musca

Drosophila

Bombyx

Aedes

Musca

Drosophila

AGAAAAACGTTTAAAAAAACAAGAAGATGATGTAGCAACCCTAGCTCAACGCCCAGTCCC 1145 GGAGAAGCGACTCAAGAAACAGGAAGATGACGTGGCAGTCTTGGCACAACGTCCCGTTCC 1157 GGAGAAACGTCTGAAGAAACAGGAAGATGATGTTCAGTITGCTGGCCCAGCGACCCGTCCC 896 TGAGAAGCGACTAAAGAAGCAAGAGGATGATGTACAAATACTAGCACAAAGGCCAGTTCC 1238

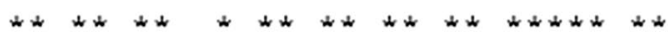

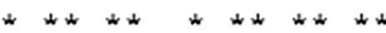

TGCCGAATGTTGCTGGATCCGACCATAGACCGACTAGTGGAATACGCACCGAACAgATA 1205 CGCTGAACTTCTGATGGATCCCACGATTGACCGACTCGTTGAATACGATCCCAACCGGTA 1217 AGCTGAATTGTTAATGGATCCTACAATTGATCGTTTGGTGGAATATGATCCAAATAGTAC 956 AACGGAGCTGCTAGTTGATCCAACCATTGATCGATTGGTCGAGTACGATCCGAACAGGTT 1298

Fig. 1 Alignment of angiopoietin-1 mRNA sequences of four insects (Bombyx, Aedes, Musca, and Drosophila). Sequence comparison was conducted with Clustal Omega based on ClustalW multiple sequence alignment method. Asterisks ( ${ }^{*}$ ) show conserved sequences
\end{abstract}

done based on the RevertAid First Strand cDNA Syn. kit Fermentas Company by the random hexamers primer.

\section{Polymerase Chain Reactions (PCR)}

All polymerase chain reactions were carried out in a $20 \mu \mathrm{l}$ total volume for 35 cycles using $2 \mu \mathrm{l}$ of the synthesized cDNA or 150 ng genomic DNA in each reaction as a template. The reaction mixture included $400 \mathrm{nM}$ of each primer, $1.5 \mathrm{mM} \mathrm{MgCl}$, 1 unit Taq DNA polymerase, $0.2 \mathrm{mM}$ dNTPs, $2 \mu \mathrm{l} 10 \mathrm{X}$ reaction buffer, and the final volume was adjusted to $20 \mu \mathrm{l}$ with the double-distilled water (DDW). The amplification program was arranged as follows: 5 min at $94{ }^{\circ} \mathrm{C}$; followed by 35 cycles of denaturation at $94{ }^{\circ} \mathrm{C}$ for $30 \mathrm{~s}$, annealing at $58^{\circ} \mathrm{C}$ for $30 \mathrm{~s}$, and extension at $72{ }^{\circ} \mathrm{C}$ for $80 \mathrm{~s}$; and an extra final extension at $72{ }^{\circ} \mathrm{C}$ for $10 \mathrm{~min}$. The amplified amplicons were purified using the DNA gel purification kit (GF-1 Vivantis, Malaysia).

\section{Sequencing}

The normal size amplicons were sequenced after gel purification, and their investigation was implemented by
Chromas (Version 2.31, 2005), DNA Star (Version 7.10, 2006), MEGA6 (Build 5110426, 2011) and nucleotide BLAST online website (https://blast.ncbi.nlm.nih.gov/ Blast.cgi?PAGE $=$ Protein). Amplicons with the sizes near the predicted range were sequenced using the GSPs forward (AnF) and reverse (AnR390) primers.

\section{Bioinformatics}

Each primer was designed by the Gene Runner (version 0.4 ) and Oligo 0.7 software. Alignments were implemented by the MEGA software (version 6.0), Clustal Omega online (https://www.ebi.ac.uk/Tools/msa/clust alo/), and their specificity for PCR was vindicated by nucleotide BLAST on NCBI (https://blast.ncbi.nlm.nih. gov/Blast.cgi).

\section{Results}

PCR reactions, which were performed using AnF1and AnR390 on the synthesized cDNA, showed amplification of amplicons near to the expected size of $390 \mathrm{bp}$, to identify the middle part sequence of $L$. sericata angiopoietin-1 with different primer mixture. The result 
of the sequencing of the midpart and its BLAST analysis revealed its high identity (85\%) with $M$. domestica (XM_020038499.1) angiopoietin mRNA sequences. These steps were undertaken based on our earlier experience and study on L. sericata collagenase [20] and An. stephensi carboxypeptidase B1 enzymes [29]. The results of this study were stored in GenBank (Accession no: MG009433).

The total alignment of the middle part of angiopoietin-1 mRNA in the GeneBank is shown below (Fig. 2). It has the highest similarity with $M$. domestica (Sequence ID: XM_020038499.1) and Drosophila arizona (XM_018013154.1) by maximum identity of $85 \%$ and $78 \%$, respectively.

Eventually, the partial sequence of angiopoietin-1 mRNA was characterized in this study that includes the coding sequence of the active site of angiopoietin-1 of $L$. sericata. Therefore, it would enable us to use this sequence to identify the 3 ' and 5' region of full sequences of angiopoietin-1 mRNA in the future to produce the relevant recombinant protein that could be used in wound healing.
A phylogenetic tree was depicted based on the angiopoietin-1 nucleic acid sequences of four fly species by the Maximum Likelihood method (Fig. 3). The maximum-likelihood bough lengths are calculated for these variant tree topologies and the highest likelihood protected as the best election yet. The phylogeny tree was drawn by using the MEGA 6.0 software. The angiopoietin-1 sequence had the most homogeneity to $M$. domestica (XM_020038499) and D. arizona (XM_018013154) nucleic acid sequences.

\section{Discussion}

The current research finding is that maggot secretion includes the differential proteins such as the groups of serine proteinase, metalloproteinase, cysteine proteinase, and growth factors that are useful in wound healing [25]. Angiopoietin is present in the family of vascular growth factors. Tan and Chong demonstrated that the dermal treatment of the recombinant protein of angiopoietinlike 4 (ANGPTL4) promoted wound healing in mice afflicted with diabetes [1]. This conclusion is according to the molecular characterization of angiopoietin-1,

\begin{tabular}{|c|c|c|}
\hline \multicolumn{3}{|c|}{ CLUSTAL O(1.2.4) multiple sequence alignment } \\
\hline current & - - TGACAGTATAATAATGTTAATGCCACCACCACCGCCTTGCCTTTGATCAAATCCAGTA & 58 \\
\hline Musca & $\begin{array}{l}\text { ATGCGGACTATAACAATGTTAATGCCACCACCACAGCCATGCCTTTGATTAAGTCCAGTA } \\
* * * * * * * * * * * * * * * * * * * * * * * * * * * * * * * * * * * * * * * * * * * * * * *\end{array}$ & 60 \\
\hline current & AGATTGATGCTTTAGTTAAACAAATACGTCCCATGGTTTCGGTTTCCGAAAAAATGGATG & 118 \\
\hline Musca & $\begin{array}{l}\text { AAATTGATGCCTTGGTTAAGAAAATCAGTCCCATGGTATCGGTATCGGAAAAAATGGATG } \\
* * * * * * * * * * * * * * * \quad \quad * * * * \quad * * * * * * * * * * * * * * * \quad * * * * * * * * * * * * * * *\end{array}$ & 120 \\
\hline current & AAGTTTGGGATGTTGTAGTGGGTACTAAATCATCGGTGGATCACTTACTGCCCAAATCGG & 178 \\
\hline Musca & $\begin{array}{l}\text { AAGTATGGGATGTTGTGGTAGGCACGAAGTCGTCGGTGGATCATTTACTACCCAAATCGG } \\
* * * * * * * * * * * * * * * * * * * * * * * * * * * * * * * * * * * * * * * * * * * * * * * * * * *\end{array}$ & 180 \\
\hline current & ATGCTTTACTAACCCAAACACAAAGACAAGAAAGAGCTATTGGTGAAATTCATCAGGACT & 238 \\
\hline Musca & $\begin{array}{l}\text { ATGCTCTTCTGACCCAAACCCAACGCCAGGAAAGGGCTATTGGTGAAATTCATCAGGATT } \\
* * * * * * * * * * * * * * * * * * * * * * * * * * * * * * * * * * * * * * * * * * * * * * * * * * *\end{array}$ & 240 \\
\hline current & TGAAAACGAAAACAAATTTGATTATTAACAACTTGGATATGGTTGAGAAGCGTTTAAAGA & 298 \\
\hline Musca & $\begin{array}{l}\text { TGAAAACGAAAACTAATTTGATTATCAATAACTTGGATATGGTGGAGAAACGTCTGAAGA } \\
* * * * * * * * * * * * * * * * * * * * * * * * * * * * * * * * * * * * * * * * * * * * * * * * * * * * *\end{array}$ & 300 \\
\hline current & AACAAGAAGATGATGTTCAGTTATTGGGGGGGGAGACCAGGGGGGAAAAAAAACTCTCAG & 358 \\
\hline Musca & 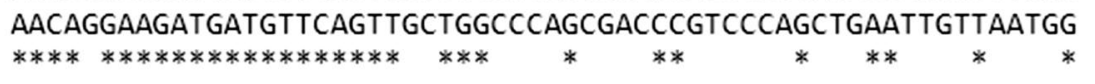 & 360 \\
\hline current & AАATTTATTCTTAACATTA-- & \\
\hline $\begin{array}{l}\text { Musca } \\
\text { Fig. } 2 \text { Alignment o } \\
\text { Musca domestica (se } \\
\text { www.ebi.ac.uk/Tool }\end{array}$ & $\begin{array}{l}\text { ATCCTACAATTGATCGTTTGG } \\
* * * * * * * \\
\text { ICleotide sequence of middle region of Lucilia sericata angiopoietin-1 (Ang1) mRNA (current) with it } \\
\text { ID: XM_020038499.1) (Musca) using Clustal Omega based on ClustalW multiple sequence alignme } \\
\text { lustalo/). The Conserved residues have been asterisked }\end{array}$ & part in \\
\hline
\end{tabular}




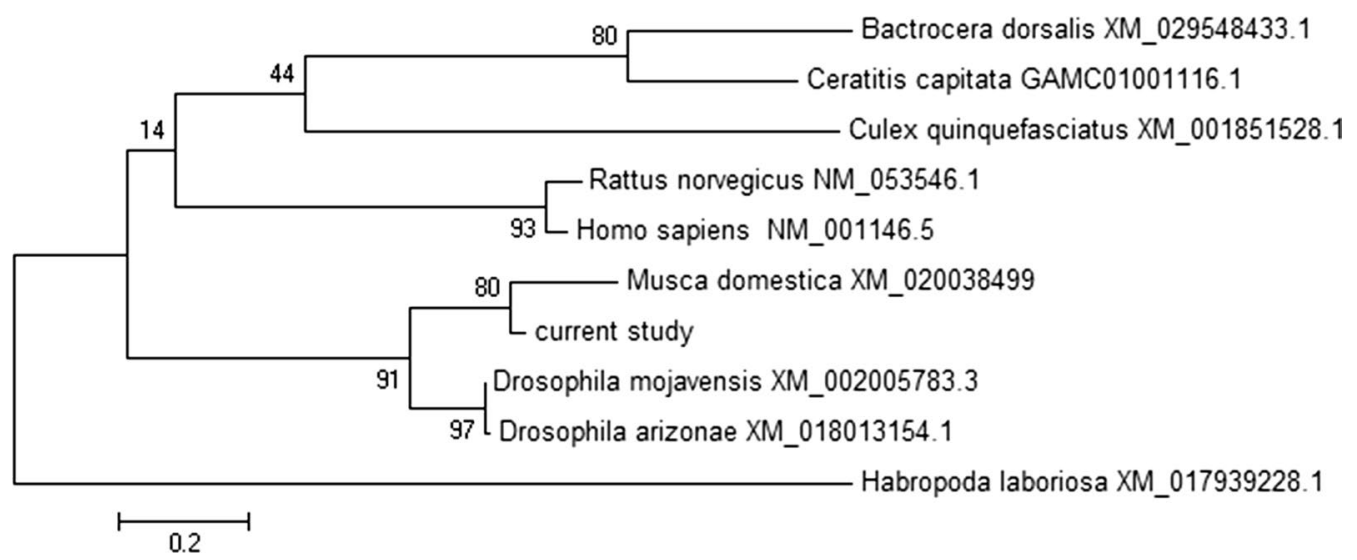

Fig. 3 Phylogenetic tree of the characterized Angiopoietin-1 (Ang1) genes of some insects and Homo sapiens. Characterized Ang1 genes of other insects and human were aligned and compared by MEGA6.0 software based on Neighbor Joining method with bootstrapping to provide confidence for phylogeny tree. The accession number of each sequence has been presented in a bracket in front of its name. The percentage of replicate trees in which the associated taxa clustered together in the bootstrap values (1000 replicates) has been shown next to the branches. The scale bar corresponds to 0.2 changes per nucleotide

which was detected for the first time from salivary glands of stage $3 \mathrm{~L}$. sericata larvae. Proteomic studies showed that L. sericata larvae secretions have three main ingredients, including proteases, small antimicrobial peptides, and growth factors [30]. Salivary glands secretions are a very favorable source of candidates for development of the new recombinant proteins that are applicable in the treatment of diseases, such as bedsore, burns, osteomyelitis, diabetic foot ulcer, cystic fibrosis, and chronic wounds [31-33]. Maggot debridement therapy (MDT) was currently resurrected due to the appearance of highly specific modifying conditions, particularly the emergence of antimicrobial resistance, which induced reinitiation of the search for optional methods to cure the chronic wounds. In this study, the middle-part sequence of angiopoietin-1 was determined. A patent has been published for the angiopoietin-like 4 (ANGPTL4) and a method of its use in wound healing [1]. It has recently been determined that ANGPTL4 is a matricellular protein involved in the regulation of metabolism and wound healing process and present in the extracellular matrix (ECM) [34]. Goh et al. demonstrated that the deficiency of ANGPTL4 in mice resulted in impeded wound re-epithelialization, diminished expression of ECM proteins, increased skin inflammation, and damaged ulcer-related angiogenesis [34]. The studies showed that 79 genes, whose interim expression portrait throughout wound healing could be grouped into their bioactive theme like cell migration, angiogenesis, proliferation, inflammation, and cell apoptosis [1]. This study succeeded in amplification of the middle part of the angiopoietin gene firstly from $L$. sericata that is the most critical insect in maggot therapy procedure. Angiopoietin, in addition to a few other enzymes like collagenase proteins, is the primary candidate in the production of recombinant protein drugs. The obtained results from the current project provide the prerequisite genomic data of angiopoietin in a famous fly with its therapeutic challenge, which would promote the designing of active new recombinant protein, an essential component for wound healing. Recently, a patent has shown that topical application of angiopoietin-4, particularly the C-terminal fibrinogen-like domain (angiopoietin-4), speeds wound closure of splint-wound model in diabetic ulcer in mice and reduces the deposit of collagen scarring at the remodeling stage of wound healing. The angiopoietin-like-4 can also be employed as an antiulcer factor $[35,36]$. To conclude, we successfully identified the mid-part of angiopoietin-1 gene in L. sericata Iranian species. This research is the first report and bioinformatics analysis of the mentioned gene in $L$. sericata that could be applied as a basis for full sequence detection of this gene in future studies.

\section{Limitations}

The timing of gene expression for the extraction of RNA, which contains the expressed gene angiopoietin, was one of the research problems. It is possible to go onwork and identify the full gene by the RACE method with the identification of the middle part in this study, which the authors are searching. Another drawback was that only a small region of the gene was characterized, so no functional characterization was plausibly performed.

\section{Abbreviations}

ANGPT1-4: Angiopoietin types 1-4; ANGPTL: Angiopoietin-like; BLAST: Basic local alignment search tool; cDNA: Circular deoxyribonucleic acid; DDW: 
Double distilled water; dNTP: Deoxynucleoside triphosphate; ECM: Extracellular matrix; FDA: Federal drug administration of USA; GF: Growth factor; GSP: Gene-specific primer; L/D: Light/dark; MDT: Maggot debridment therapy; mRNA: Messenger ribonucleic acid; PCR: Polymerase chain reactions; RT: Reverse transcription.

\section{Acknowledgements}

The present research is supported by the Research Fund of the Shiraz University of Medical Sciences (SUMS) project numbers 1396-01-04-14466 to Dr. Hamzeh Alipour.

\section{Authors' Contributions}

MS-N conducted experiments, wrote, and edited the figures of the first draft. HA and SE performed molecular biology and experimental set up to produce the particles. MDM-F contributed to the design, analysis, and manuscript preparation. All authors read and approved the final manuscript.

\section{Funding}

Grant number 1396-01-04-14466 awarded to the second author.

\section{Availability of data and materials}

The datasets used and/or analyzed during the current study are available from the corresponding author on reasonable request.

\section{Ethics approval and consent to participate}

Not applicable.

\section{Consent for publication}

Not applicable.

\section{Competing interests}

The authors declare that they have no competing interests.

Received: 22 February 2020 Accepted: 16 June 2020

Published online: 01 July 2020

\section{References}

1. Tan NS, Chong HCK. Angiopoietin-like 4 and a method of its use in wound healing. Google Patents; 2018.

2. Rizov M, Andreeva P, Dimova I. Molecular regulation and role of angiogenesis in reproduction. Taiwan J Obstet Gynecol. 2017;56(2):127-32.

3. Lobov IB, Brooks PC, Lang RA. Angiopoietin-2 displays VEGF-dependent modulation of capillary structure and endothelial cell survival in vivo. Proc Natl Acad Sci. 2002;99(17):11205-10.

4. Kern TS. Contributions of inflammatory processes to the development of the early stages of diabetic retinopathy. J Diabetes Res. 2007; 2007:95103.

5. Nadar S, Blann A, Beevers D, Lip G. Abnormal angiopoietins $1 \& 2$, angiopoietin receptor Tie-2 and vascular endothelial growth factor levels in hypertension: relationship to target organ damage [a sub-study of the Anglo-Scandinavian Cardiac Outcomes Trial (ASCOT)]. J Intern Med. 2005;258(4):336-43.

6. Elpek GÖ. Angiogenesis and liver fibrosis. World J Hepatol. 2015;7(3):377.

7. Visconti RP, Richardson CD, Sato TN. Orchestration of angiogenesis and arteriovenous contribution by angiopoietins and vascular endothelial growth factor (VEGF). Proc Natl Acad Sci. 2002;99(12):8219-24.

8. Vinodbhai PN. Angiogenesis. Mehsana, Gujarat: SK Patel College of Pharmaceutical Education \& Research; 2007.

9. Katoh Y, Katoh M. Comparative integromics on Angiopoietin family members. Int J Mol Med. 2006;17(6):1145-9.

10. Zhang B, Khalaf $H$, Sirsjö A, Bengtsson T. Gingipains from the periodontal pathogen Porphyromonas gingivalis play a significant role in regulation of angiopoietin 1 and angiopoietin 2 in human aortic smooth muscle cells. Infect Immun. 2015;83(11):4256-65.

11. Alipour H, Darabi H, Dabbaghmanesh T, Bonyani M. Entomological study of sand flies (Diptera: Psychodidae: Phlebotominae) in Asalouyeh, the heartland of an Iranian petrochemical industry. Asian Pac J Trop Biomed. 2014;4:S242-S245245.
12. Hasnain S, Sheikh NH. Knowledge and practices regarding foot care in diabetic patients visiting diabetic clinic in Jinnah Hospital, Lahore. J Pak Med Assoc. 2009;59(10):687.

13. Nikokar I, Tishayar A, Flakiyan Z, Alijani K, Rehana-Banisaeed S, Hossinpour $\mathrm{M}$, et al. Antibiotic resistance and frequency of class 1 integrons among Pseudomonas aeruginosa, isolated from burn patients in Guilan, Iran. Iran J Microbiol. 2013;5(1):36.

14. Jafari F, Hamidian M, Rezadehbashi M, Doyle M, Salmanzadeh-ahrabi S, Derakhshan F, et al. Prevalence and antimicrobial resistance of diarrheagenic Escherichia coli and Shigella species associated with acute diarrhea in Tehran, Iran. Can J Infect Dis Med Microbiol. 2009;20(3):e56-e62.

15. Ngambo LAP, Higgins SJ, Kain KC. Angiopoietin-based interventions for treating cerebral malaria. Google Patents; 2017.

16. Yang X, Cheng Y, Su G. A review of the multifunctionality of angiopoietin-like 4 in eye disease. Biosci Rep. 2018;38(5):BSR20180557.

17. Powers JG, Higham C, Broussard K, Phillips TJ. Wound healing and treating wounds: chronic wound care and management. J Am Acad Dermatol. 2016;74(4):607-25.

18. Whitaker IS, Twine C, Whitaker MJ, Welck M, Brown CS, Shandall A Larval therapy from antiquity to the present day: mechanisms of action, clinical applications and future potential. Postgrad Med J. 2007;83(980):409-13.

19. Sherman RA, Wyle F, Vulpe M. Maggot therapy for treating pressure ulcers in spinal cord injury patients. J Spinal Cord Med. 1995;18(2):71-4

20. Alipour H, Raz A, Zakeri S, Djadid ND. Molecular characterization of matrix metalloproteinase-1 (MMP-1) in Lucilia sericata larvae for potential therapeutic applications. Electron J Biotechnol. 2017;29:47-56.

21. Davydov L. Maggot therapy in wound management in modern era and a review of published literature. J Pharm Pract. 2011;24(1):89-93.

22. Joshi S, Khan R, Sharma M, Kumar L, Sharma A. Angiopoietin-2: a potential novel diagnostic marker in multiple myeloma. Clin Biochem. 2011:44(8-9):590-5.

23. Akbarzadeh K, Rafinejad J, Alipour H, Biglarian A. Human myiasis in Fars province, Iran. Southeast Asian J Trop Med Public Health. 2012;43(5):1205.

24. Rafinejad J, Akbarzadeh K, Rassi Y, Nozari J, Sedaghat MM, Hosseini M, et al. Traumatic myiasis agents in Iran with introducing of new dominant species, Wohlfahrtia magnifica (Diptera: Sarcophagidae). Asian Pac J Trop Biomed. 2014;4(6):451-5.

25. Alipour H, Raz A, Zakeri S, Djadid ND. Therapeutic applications of collagenase (metalloproteases): a review. Asian Pac J Trop Biomed. 2016;6(11):975-81.

26. Moemenbellah-Fard MD, Keshavarzi D, Fereidooni M, Soltani A. First survey of forensically important insects from human corpses in Shiraz, Iran. J Forensic Leg Med. 2018;54:62-8.

27. Frederickx C, Dekeirsschieter J, Verheggen FJ, Haubruge E. Responses of Lucilia sericata Meigen (Diptera: Calliphoridae) to cadaveric volatile organic compounds. J Forensic Sci. 2012;57(2):386-90.

28. Khamsehnejad MI, Djadid ND, Raz A. Identification, Molecular Characterization, and In Silico Structural Analysis of Carboxypeptidase B2 of Anopheles stephensi. J Med Entomol. 2018;56(1):72-85.

29. Raz A, Djadid ND, Zakeri S. Molecular characterization of the carboxypeptidase B1 of Anopheles stephensi and its evaluation as a target for transmission-blocking vaccine (TBV). Infect Immun. 2013;81(6):2206-16.

30. Tonk M, Vilcinskas A. The medical potential of antimicrobial peptides from insects. Curr Top Med Chem. 2017;17(5):554-75.

31. Van der Plas MJ, Jukema GN, Wai S-W, Dogterom-Ballering HC, Lagendijk EL, van Gulpen C, et al. Maggot excretions/secretions are differentially effective against biofilms of Staphylococcus aureus and Pseudomonas aeruginosa. J Antimicrob Chemother. 2007;61(1):117-22.

32. Sherman RA, Cooper EL. Biotherapy: medicinal maggots and invertebrate immunology from the clinician's perspective. In: Cooper EL, editor. Advances in comparative immunology. Cham: Springer; 2018. p. 991-5.

33. Jordan A, Khiyani N, Bowers SR, Lukaszczyk JJ, Stawicki SP. Maggot debridement therapy: a practical review. Int J Acad Med. 2018;4(1):21.

34. Zhu P, Goh YY, Chin HFA, Kersten S, Tan NS. Angiopoietin-like 4: a decade of research. Biosci Rep. 2012;32(3):211-9. 
35. Leu J-G, Chiang M-H, Chen C-Y, Lin J-T, Chen H-M, Chen Y-L, et al. Adenine accelerated the diabetic wound healing by PPAR delta and angiogenic regulation. Eur J Pharmacol. 2018;818:569-77.

36. Hu MS, Borrelli MR, Lorenz HP, Longaker MT, Wan DC. Mesenchymal stromal cells and cutaneous wound healing: a comprehensive review of the background, role, and therapeutic potential. Stem Cells Int. 2018;2018:6901983.

\section{Publisher's Note}

Springer Nature remains neutral with regard to jurisdictional claims in published maps and institutional affiliations.
Ready to submit your research? Choose BMC and benefit from:

- fast, convenient online submission

- thorough peer review by experienced researchers in your field

- rapid publication on acceptance

- support for research data, including large and complex data types

- gold Open Access which fosters wider collaboration and increased citations

- maximum visibility for your research: over $100 \mathrm{M}$ website views per year

At BMC, research is always in progress.

Learn more biomedcentral.com/submissions 